\title{
Agências de rating e desenvolvimentismo: há espaço para conciliação?
}

\author{
Credit rating agencies and developmentalism: is there room for conciliation?
}

DOI: https://doi.org/10.22456/2178-8839.100528

Pedro Lange Netto Machado Universidade do Estado do Rio de Janeiro, Rio de Janeiro, Brasil pedrolangenm@gmail.com

\section{Resumo}

O artigo analisa o comportamento das agências de rating frente a implementação de políticas desenvolvimentistas pelos governos de Lula da Silva e Dilma Rousseff. Busca-se, a partir de uma perspectiva pós-keynesiana, associada a observações teóricas e empíricas da literatura acerca da integração de economias emergentes à globalização financeira e da atuação das agências no sistema financeiro internacional, compreender as restrições impostas por essas empresas a políticas econômicas alternativas à ortodoxia neoliberal que propagam e que orientam suas avaliações. A hipótese subjacente é que o caráter pró-cíclico de sua atuação abre espaço para que tolerem ou mesmo estimulem a adoção de um instrumental desenvolvimentista em momentos específicos de crescimento econômico. Isto é sugerido pelos ratings que atribuíram aos governos em questão quando da adoção de estratégias novo ou social-desenvolvimentistas por determinados períodos, sendo também observado a partir dos relatórios que publicaram e demais manifestações de seus executivos. Pretende-se, com o trabalho, refletir sobre as perspectivas de implementação de estratégias desenvolvimentistas no contexto de globalização financeira, assim como mais bem compreender o propósito e o modus operandi das agências de rating, que despontam como atores ainda pouco explorados academicamente.

Palavras-chave: Agências de rating; Globalização financeira; Desenvolvimentismo.

\section{Abstract}

The article analyzes credit rating agencies' behavior in face of the adoption of developmentalist policies by Lula da Silva and Dilma Rousseff governments. It aims, from a post-Keynesian perspective, associated with theoretical and empirical observations of the literature about emerging economies' integration to financial globalization and the role of the agencies in the international financial system, to understand the restrictions imposed by these companies on alternative economic policies to the neoliberal orthodoxy that guide their evaluations. The working hypothesis is that the pro-cyclical nature of their activities makes room for them to tolerate or even encourage the adoption of developmentalist instruments at specific times of economic growth. This is suggested by the ratings they issued to Brazilian public bonds during the regarded period, when new or social-developmental strategies were adopted, and it is also observed in their published reports and in statements from their executives. It is intended, with this research, to reflect on the prospects for implementing developmentalist strategies in the context of financial globalization, as well as to better understand the purpose and modus operandi of credit rating agencies, which are actors still little explored academically.
\end{abstract}

Keywords: Credit rating agencies; Financial globalization; Developmentalism. 


\section{Introdução}

O contexto de globalização financeira impõe restrições à adoção de políticas econômicas que desvirtuam da ortodoxia neoliberal. Esta realidade pode ser observada a partir da atuação das agências de rating, que orientam fluxos financeiros em escala global e usam de sua prerrogativa como avaliadoras de risco para pressionar governos nacionais a aderirem aos preceitos do Consenso de Washington. Nesse contexto, estratégias desenvolvimentistas se tornam de difícil implementação, sobretudo em economias emergentes, sobre as quais as assimetrias financeiras e monetárias da globalização financeira incidem com maior força.

Entretanto, a experiência brasileira ao longo dos governos do Partido dos Trabalhadores (PT) parece destoar dessa tendência. Durante as gestões de Lula e de Dilma, uma gama de instrumentos desenvolvimentistas foi utilizada, ao mesmo tempo em que o Brasil alcançou as melhores avaliações atribuídas pelas agências de rating em sua história. Diante disso, emerge a pergunta que figura no título deste trabalho e que orienta a pesquisa: há espaço para conciliação entre as avaliações das agências de rating e práticas desenvolvimentistas? A análise proposta se realiza a partir da confrontação das políticas de fato levadas a cabo pelos governos petistas com os ratings, relatórios e manifestações emitidas por Standard \& Poor's (S\&P), Moody's e Fitch Ratings em relação ao país. Desta feita, o argumento subjacente é que o caráter pró -cíclico da atuação dessas agências pode atenuar seu alinhamento ideológico, viabilizando que tolerem ou mesmo estimulem a adoção de instrumentos desenvolvimentistas em momentos de crescimento econômico e de maior liquidez internacional. Esgotadas estas condições, porém, sua adesão à ortodoxia neoliberal volta a se evidenciar.

O artigo se estrutura em três seções, além desta introdução e de uma conclusão. Na segunda seção, busca-se situar as agências de rating e as economias emergentes no contexto de globalização financeira, levando-se em conta contribuições teóricas sobre a margem de manobra que se apresenta a seus respectivos governos nacionais e observações da literatura acerca da atuação das agências no sistema financeiro internacional. A terceira seção apresenta duas vertentes do desenvolvimentismo - o novo e o social desenvolvimentismo - em seus aspectos teóricos e em sua implementação prática durante os governos do PT. Sobre essas bases, desenvolve-se a análise, na quarta seção, sobre o comportamento das agências frente às políticas desenvolvimentistas então implementadas. As conclusões apontam para a plausibilidade da hipótese proposta.

\section{Agências de rating e economias emergentes na globalização financeira}

Em artigo publicado no The New York Times, após o fim da Guerra Fria, Friedman (1995) anunciava que o mundo seguia tendo duas superpotências: "Há os Estados Unidos e há a Moody's. Os Estados Unidos podem destruir um país lançando-lhe bombas, enquanto a Moody's pode fazer o mesmo rebaixando a nota de seus títulos. " A declaração refletia o poder que as agências de rating adquiriram ao longo do último quarto do século XX, como uma das expressões do conjunto de processos comumente denominado como globalização financeira. No contexto de mercados de capitais globalizados, estas empresas adquirem proeminência, uma vez que cumprem a função de informar aos investidores acerca da credibilidade de instrumentos de dívida emitidos e negociados por empresas e governos nacionais ou subnacionais. No caso de Estados nacionais, as agências o fazem mediante a atribuição de um rating soberano, que traduz, em um conceito, os riscos inerentes à aquisição de títulos de sua dívida pública por investidores.

Historicamente, as três agências supracitadas - S\&P, Moody's e Fitch - monopolizam o setor global de risco soberano. Os ratings por elas atribuídos possuem considerável impacto sobre o rumo de economias nacionais, uma vez que incidem sobre o fluxo de entrada e de saída de capitais e sobre as condições de financiamento da dívida pública, isto é, sobre os juros exigidos por credores para que se proceda ao investimento em títulos públicos do país em questão. Em linhas

${ }^{1}$ Tradução do original: "There is the U.S. and there is Moody's. The U.S. can destroy a country by leveling it with bombs; Moody's can destroy a country by downgrading its bonds." 
gerais, as grades de notas das três referidas empresas possuem correspondência entre si e podem ser divididas em dois blocos, retratados no quadro abaixo: o que contempla os ratings pertencentes ao grau de investimento e os que são categorizados como grau especulativo. No caso dos primeiros, indica-se que o país goza de alta credibilidade em relação a sua capacidade de honrar os compromissos de dívida contraídos, ao passo que o segundo sugere que há risco de calote. Como consequência, a obtenção de boas avaliações - e em especial, do grau de investimento - se coloca como um imperativo à estabilidade do Balanço de Pagamentos, o que, na prática, faz com que governos nacionais busquem evitar qualquer tipo de atrito com as agências (YWATA, 2012).

Quadro 1-Grade de notas Moody's, S\&P e Fitch Ratings.

\begin{tabular}{|c|c|c|}
\hline \multicolumn{3}{|c|}{ Grau de Investimento } \\
\hline S\&P & Moody's & Fitch \\
\hline AAA & Aaa & AAA \\
\hline $\mathrm{AA}+$ & $\mathrm{Aa} 1$ & $\mathrm{AA}+$ \\
\hline $\mathrm{AA}$ & $\mathrm{Aa} 2$ & $\mathrm{AA}$ \\
\hline $\mathrm{AA}-$ & $\mathrm{Aa} 3$ & $\mathrm{AA}-$ \\
\hline $\mathrm{A}+$ & $\mathrm{A} 1$ & $\mathrm{~A}+$ \\
\hline $\mathrm{A}$ & $\mathrm{A} 2$ & $\mathrm{~A}$ \\
\hline $\mathrm{A}-$ & $\mathrm{A} 3$ & $\mathrm{~A}-$ \\
\hline $\mathrm{BBB}+$ & $\mathrm{Baa} 1$ & $\mathrm{BBB}+$ \\
\hline $\mathrm{BBB}$ & $\mathrm{Baa} 2$ & $\mathrm{BBB}$ \\
\hline $\mathrm{BBB}-$ & $\mathrm{Baa} 3$ & $\mathrm{BBB}-$ \\
\hline
\end{tabular}

\begin{tabular}{|c|c|c|}
\hline \multicolumn{3}{|c|}{ Grau Especulativo } \\
\hline S\&P & Moody's & Fitch \\
\hline BB+ & Ba1 & BB+ \\
\hline BB & Ba2 & BB \\
\hline BB- & Ba3 & BB- \\
\hline B+ & B1 & B+ \\
\hline B & B2 & B \\
\hline B- & B3 & B- \\
\hline CCC+ & Caa1 & CCC-D \\
\hline CCC & Caa2 & - \\
\hline CCC- & Caa3 & - \\
\hline CC & Ca & - \\
\hline C & C & - \\
\hline SD & - & - \\
\hline D & - & - \\
\hline
\end{tabular}

Fonte: elaboração própria a partir de dados da Moody's (2020), S\&P (2020) e Fitch (2020).

Em outras palavras, a atuação das agências de rating está diretamente relacionada ao que Ocampo (2011) denomina como "dominância do Balanço de Pagamentos" na dinâmica macroeconômica das economias emergentes integradas à globalização financeira. Como observado por Paula, Fritz e Prates (2015), a liberalização financeira nesses países - em meio a um sistema monetário internacional hierarquizado, onde suas moedas ocupam posição periférica e seus títulos de dívida pública apresentam menor liquidez - acarreta instabilidades macroeconômicas decorrentes da volatilidade que os fluxos de capitais em suas economias adquirem. Estes, por sua vez, possuem fontes majoritariamente exógenas, estando associados à administração das taxas de juros em economias centrais - sobretudo a dos Estados Unidos, emissor da moeda central no sistema monetário global - e à cambiante aversão ao risco por parte de investidores no sistema financeiro internacional. É neste cenário que se inserem as informações de risco difundidas pelas agências, que acabam por se constituir em uma das referidas origens exógenas que impactam sobre o fluxo de recursos financeiros nesses países.

Neste papel reside também a explicação para que S\&P, Moody’s e Fitch se constituam em centros nevrálgicos na dinâmica financeira global. Como o substrato ideológico da globalização financeira se fundamenta na teoria da eficiência dos mercados e da racionalidade dos agentes que nele operam, a função de mitigar assimetrias informacionais, em parte desempenhada pelas agências, ganha proeminência. Com efeito, uma melhor alocação de recursos financeiros possibilitada pelo acesso a informações que auxiliem decisões de investimento beneficiaria, em última instância, as próprias economias emergentes, onde o capital seria escasso e as oportunidades para se investir, abundantes. Na prática, 
porém, a liberalização da conta de capital desses países acabou por torná-los reféns da confiança depositada por investidores em suas economias. Esta, uma vez revertida, pode resultar em uma súbita fuga de capitais e nas consequências deletérias daí decorrentes para a economia. Como resultado, de forma preventiva e permanente, seus governos são constrangidos a adotar altas taxas de juros e austeridade fiscal, o que pode acabar por comprometer a implementação de suas agendas de governo e o próprio crescimento econômico (CARVALHO, 2004).

Tal realidade vem colocando em xeque a própria viabilidade de regimes democráticos no contexto de globalização financeira, uma vez que governantes, temendo reações negativas do mundo financeiro, frequentemente acabam por preterir as demandas de seus eleitores em benefício das de investidores (RODRIK, 2012; STREECK, 2018). No caso das economias emergentes, Mosley (2003) percebe que a vigilância imposta pelo mercado vai além de indicadores macroeconômicos, o que as tornam passíveis de serem punidas - mediante uma maior precificação de seus títulos públicos - em decorrência da ideologia político partidária de seus governantes e das políticas que implementam em nível microeconômico. Já Campello (2015) observa que a margem de manobra de governos sul-americanos para desvirtuar da ortodoxia econômica é condicionada por duas variáveis exógenas: os preços das commodities de cuja exportação são altamente dependentes e as condições de liquidez internacional, que reflete uma maior ou menor aversão ao risco por parte de investidores no mercado financeiro. Em outras palavras, a conjuntura internacional incidiria diretamente sobre as possibilidades de implementação de uma agenda desalinhada aos interesses de investidores e que poderia, assim, comprometer a confiança da qual depende a estabilidade do Balanço de Pagamentos.

Em teoria, tal risco deveria ser mitigado a partir da adesão ao receituário de políticas frequentemente propagadas por instituições da governança econômica global desde o começo da década de 1990, reconhecidas sob a alcunha de Consenso de Washington ${ }^{2}$. Este, como destacado por Williamson (1993), contempla uma série de medidas que visariam a adequar as economias nacionais, em especial as emergentes, à realidade de globalização financeira, supostamente minimizando os riscos de ocorrência de fugas de capitais. Nesse sentido, as orientações - que, na realidade, acabavam frequentemente por ser impostas por organizações internacionais - abrangem políticas como: i) liberalização financeira, de modo a fazer com que taxas de juros sejam determinadas por agentes do mercado; ii) disciplina fiscal, para eliminar o risco de que déficits sejam financiados com recurso à inflação; iii) restrição de gastos públicos; iv) liberalização comercial e remoção de barreiras ao investimento estrangeiro direto; v) privatizações de empresas públicas; vi) independência dos bancos centrais, de modo a blindá-los de demandas democráticas que possam gerar pressões inflacionárias; dentre outras. O pressuposto básico dessas ideias, em sintonia com a ortodoxia econômica, é que a intervenção estatal na economia é sempre desestabilizadora e nunca pode produzir resultados positivos no estímulo ao crescimento econômico.

É diante dessa realidade que a literatura percebe o alinhamento irrestrito das agências de rating aos preceitos do Consenso de Washington. A partir de sua prerrogativa como avaliadoras de risco, essas empresas, na prática, pressionam governos nacionais a se alinharem à ortodoxia econômica, o que se reflete na atribuição de notas piores aos que resistem a estas ideias e em críticas públicas divulgadas nos relatórios em que avaliam a gestão das economias nacionais (SINCLAIR, 2005; YWATA, 2012; MACHADO, 2018). Nesta direção, pesquisas empíricas observam também que países governados por partidos de esquerda tendem a ser mais mal avaliados em decorrência da ideologia político-partidária de seus governos uma realidade percebida tanto em economias centrais (BARTA; JOHNSTON, 2017) como nas emergentes (VAALER; SCHRAGE; BLOCK, 2006).

Ademais, na esteira de crises econômicas ocasionadas ou potencializadas por avaliações equivocadas ${ }^{3}$ das agências, o próprio rating vem sendo amplamente questionado e criticado como instrumento de classificação de risco -

\footnotetext{
${ }^{2} \mathrm{~A}$ bem da verdade, instituições da governança econômica global vêm gradativamente reconhecendo as instabilidades decorrentes da adesão irrestrita a esse receituário, especialmente no pós-crise de 2008, e flexibilizando suas orientações, sobretudo em relação à austeridade fiscal como imperativo na política econômica e à. Exemplos nesse sentido são observados em recentes posicionamentos do FMI, assim como da UNCTAD e do Banco Mundial embora tal tendência não se aplique às agências de rating, dado o caráter privado da atividade que exercem. Sobre essa questão, ver Blyth (2017).

${ }^{3}$ Exemplos relevantes são a crise financeira do sudeste asiático, de 1997, a crise em torno da falência da Enron, em 2001 e, principalmente, a crise econômica global desencadeada em 2008. Para um maior detalhamento da participação das agências nessas crises, ver Kruck (2016) e Sinclair (2005).
} 
sobretudo porque, nessas reiteradas ocasiões, seu caráter pró-cíclico acabou por se revelar ${ }^{4}$. É diante disso que Sinclair (2005) identifica as agências como atores eminentemente políticos, que buscam atuar sobre a economia política estatal lançando mão do status que desfrutam como entidades técnicas e neutras. A partir desta condição, propagariam os preceitos ortodoxos que pautam suas ações, visando, em última instância, a fazer convergir a gestão de economias nacionais em torno dos mesmos. No mesmo sentido, Paudyn (2014) denuncia o caráter falsa e pretensamente científico do rating, que, forjado a partir de uma série de inconsistências, acabaria por conferir longevidade à agenda neoliberal, blindando-a e a retirando do debate político. Em todo caso, a despeito destas críticas e de seus envolvimentos em crises de grandes proporções, as agências seguem desfrutando de considerável influência sobre decisões de investimento nos mercados de capitais globalizados (BINICI; HUTCHISON; MIAO, 2018).

Em suma, o que se pode depreender dessas observações é que a atuação das agências de rating parece ser menos técnica e mais política do que a posição que ocupam no sistema financeiro internacional deixaria, a priori, transparecer. Ao se alinharem ideologicamente à ortodoxia neoliberal e propagarem os preceitos do Consenso de Washington, tais empresas acabam por atuar politicamente na esfera estatal e se constituem em entraves a políticas econômicas alternativas a esse receituário. Assim, é de se esperar que a adoção de políticas desenvolvimentistas seja mais difícil em meio a este cenário de pressão, sobretudo para economias emergentes, dadas as assimetrias financeira e monetária que a globalização financeira lhes impõe. É sobre este tema que as seções seguintes se debruçarão.

\section{Variantes do desenvolvimentismo durante os governos do PT}

$\mathrm{Na}$ esteira do fracasso do Consenso de Washington em promover o desenvolvimento econômico de economias emergentes, debates em torno de estratégias desenvolvimentistas voltaram a ganhar força. No Brasil, a agenda de pesquisa sobre o tema vem se estruturando em torno de duas vertentes, que, em alguma medida, estiveram presentes nos governos do Partido dos Trabalhadores (PT), entre 2003 e 2014 - o que vai ao encontro da observação de Fonseca (2014), que percebe o desenvolvimentismo como fenômeno que intersecciona o mundo das ideias e o da prática política. Tratam-se do novodesenvolvimentistmo e do social-desenvolvimentismo, que, a despeito de convergirem na rejeição de preceitos ortodoxos e do objetivo de promover a sofisticação da estrutura produtiva nacional com distribuição de renda, possuem também marcadas diferenças entre si quanto aos meios e instrumentos necessários ao alcance deste fim. Diante destas considerações e da referida observação de Fonseca (2014), as duas subseções seguintes discorrem, respectiva e separadamente, acerca de desenvolvimentos teóricos e da implementação prática, no Brasil, relativas a essas duas correntes do pensamento desenvolvimentista.

\section{Considerações teóricas acerca do novo e do social-desenvolvimentismo}

Como destaca Bresser-Pereira (2009), o novo-desenvolvimentismo é uma estratégia de desenvolvimento nacional baseada em preceitos macroeconômicos keynesianos e estruturalistas, que contempla um conjunto de valores, ideias, instituições e políticas econômicas voltadas a promover o catch up industrial de economias de renda média em relação às desenvolvidas. Esta abordagem parte da identificação de dois problemas macroeconômicos fundamentais que a priori impediriam tal objetivo: i) a tendência de os salários crescerem abaixo da produtividade industrial devido à oferta ilimitada de mão-de-obra nessas economias; ii) a tendência à sobrevalorização de suas moedas, o que ocorre em decorrência tanto do que é conhecido por doença holandesa ${ }^{5}$ quanto dos fluxos líquidos de capital externo. Como resposta

\footnotetext{
${ }^{4}$ Um estudo seminal sobre o caráter pró-cíclico da avaliação das agências é apresentado por Ferri, Liu e Stiglitz (1999).

${ }^{5}$ Conforme definição de Bresser-Pereira e Gala (2010), a doença holandesa pode ser definida como a "sobreapreciação crônica da taxa de câmbio de um país causada por rendas ricardianas que o país obtém ao explorar recursos abundantes e baratos, cuja produção comercial é compatível com uma taxa
} 
a essas tendências, o novo-desenvolvimentismo postula que os salários devem crescer em linha com a produtividade e que a taxa de câmbio deve neutralizar a tendência à valorização cambial.

O cerne da estratégia novo-desenvolvimentista exige, assim, a manutenção da taxa de câmbio em patamares que garantam a competitividade da indústria nacional - o que pode demandar mecanismos de controle de capitais, voltados a garantir, em um primeiro momento, o câmbio desvalorizado, que progressivamente deveria atingir um ponto de equilíbrio para o setor industrial. A partir desta condição, estimular-se-iam investimentos no setor privado, o que daria início ao processo de reindustrialização voltado, a princípio, à exportação de bens manufaturados. Com este setor se tornando superavitário e os salários crescendo em linha com a produtividade, uma melhor distribuição de renda seria também, em última instância, alcançada. Paralelamente, esta estratégia exigiria também uma política fiscal balanceada e o acúmulo de reservas internacionais pelo Banco Central - o que permitiria ao governo agir contraciclicamente em momentos de crise , assim como uma taxação progressiva dos setores rentistas da sociedade (BRESSER-PEREIRA, 2009).

Em suma, segundo o novo-desenvolvimentismo, o catch up industrial exigiria a manipulação de variáveis macroeconômicas, em especial da taxa de câmbio, de modo a se estimular o setor privado a promover os investimentos necessários à reindustrialização do país. Neste processo, o setor de exportação de bens manufaturados desponta como estratégico. Além disso, destoando da ortodoxia econômica, estaria entre as tarefas do Banco Central não apenas o controle inflacionário, mas também a geração de empregos e a manutenção da taxa cambial necessária à consecução dos objetivos mencionados.

Se para o novo-desenvolvimentismo o desenvolvimento das forças produtivas aparece como principal meta, o social-desenvolvimentismo, em outra linha, desloca para o eixo social a base de sua estratégia desenvolvimentista (CARNEIRO, 2012). Denominada por Bastos (2012) como "desenvolvimentismo distributivo orientado pelo Estado", esta corrente desponta como uma interpretação ex-post do crescimento "sob o empuxe das pressões para elevação do salário mínimo, do crédito ao consumidor e das políticas sociais a partir de 2005". Daí que Carneiro (2012) observa uma maior fragmentação em suas reflexões teóricas, assim como sua menor inserção em agendas de pesquisa acadêmica. Ademais, também como consequência desta realidade, esta corrente não parece estar associada a um único regime macroeconômico nem parece contemplar uma estratégia sustentável de desenvolvimento de longo prazo.

Em todo caso, o que se pode depreender de seus postulados teóricos é que o desenvolvimento econômico e a sofisticação da estrutura produtiva nacional demandariam a conformação de um mercado doméstico de massa, constituído a partir de uma melhor distribuição de renda, que, por sua vez, estimularia investimentos públicos e privados, sobretudo em infraestrutura. Como observa Carneiro (2012 apud FRITZ; PAULA; PRATES, 2017), tal distribuição de renda passaria pela expansão do emprego, pelo aumento do salário mínimo e pelo maior acesso ao crédito pelo consumidor. Buscando uma maior sustentabilidade no longo prazo, investimentos autônomos em infraestrutura econômica e social, tanto de caráter público quanto privado, apareceriam como um imperativo. Neste processo, eventuais restrições advindas do Balanço de Pagamentos devem ser compensadas pela exportação de commodities e por uma melhor inserção do país nestas cadeias de valor. No longo prazo, a dinamização do mercado interno deve gerar efeitos de escala na produção industrial doméstica, o que também se beneficiaria de uma política industrial ativa voltada a atender esta demanda. Em última instância, este ciclo virtuoso seria também revertido ao setor exportador.

Por conseguinte, a estratégia social-desenvolvimentista se constrói mediante o fomento ao consumo doméstico, tendo como catalisador a distribuição de renda. Diferentemente do novo-desenvolvimentismo, no entanto, as políticas macroeconômicas são, por ora, pouco exploradas nesta corrente de pensamento. Desta feita, tanto a estabilidade dos preços quanto a apreciação cambial permaneceriam como questões a serem esclarecidas (FRITZ; PAULA; PRATES, 2017).

de câmbio de equilíbrio corrente claramente mais apreciada do que a taxa de câmbio de equilíbrio industrial — a taxa que viabiliza os demais setores econômicos produtores de bens comercializáveis que utilizam tecnologia no estado da arte mundial." 


\section{A prática desenvolvimentista ao longo dos governos do PT}

Embora fuja ao escopo deste artigo uma análise pormenorizada das políticas econômicas implementadas durante os governos petistas, algumas considerações nesse sentido serão necessárias para tentar enquadrá-las nas estratégias de desenvolvimento apresentadas até aqui. Com efeito, as variações de políticas levadas a cabo em diferentes níveis ao longo das gestões de Lula e Dilma permitem a identificação de um instrumental variado de medidas, orientadas tanto pela ortodoxia econômica quanto pelas abordagens desenvolvimentistas apresentadas previamente. Assim, ainda que não se possa afirmar que os governos petistas tenham, de fato, constituído experiências desenvolvimentistas (PAULANI, 2017; PRATES; FRITZ; PAULA, 2018), a identificação de algumas de suas ações como tal será objeto desta subseção.

Quanto a esta questão, Paula, Santos e Moura (2020) observam que, de modo geral, no âmbito das políticas sociais e da política econômica, os governos do PT estiveram mais próximos ao social-desenvolvimentismo - sobretudo quando consideradas as políticas de dinamização do mercado doméstico, como as de valorização do salário mínimo e de facilitação do acesso ao crédito mediante uma forte atuação dos bancos públicos. Além disso, investimentos em infraestrutura, com amplo apoio do BNDES, figuraram entre as políticas convergentes com a abordagem social-desenvolvimentista que perpassam, em especial, os anos de governo Lula.

No plano macroeconômico, no entanto, o governo Lula permaneceu orientado pela ortodoxia neoliberal, tendo sido beneficiado pela conjuntura internacional favorável em que se situou e que lhe permitiu lançar mão das políticas sociais e de promoção do mercado doméstico que o caracterizou. Em outras palavras, a margem de manobra de que desfrutou foi condicionada pelos altos preços das commodities exportadas pelo país e pelas condições de liquidez internacional do período (CAMPELLO, 2015). Conforme Bresser-Pereira (2013), o êxito obtido logo se mostraria insustentável se não se rompesse com a herança macroeconômica que as altas taxas de juros e o câmbio apreciado legaram ao país, o que inviabilizava a retomada do desenvolvimento industrial. Tal seria a inspiração para a Nova Matriz Econômica (NME), que, inspirada em preceitos novo-desenvolvimentistas, seria lançada em meados de 2011 pelo governo Dilma.

Como observa Singer (2018), o ensaio desenvolvimentista em que consistiu a NME seria de curta duração, com seu desmonte iniciado já em 2013, quando da retomada da alta da taxa Selic pelo Banco Central. Paralelamente, o esforço pela desvalorização cambial carregaria, durante o período, uma série de ambiguidades, decorrentes da turbulenta conjuntura externa em que se situou. Novamente, conquanto não seja um objetivo deste trabalho detalhar os desdobramentos de política econômica do período, cabe ressaltar que a NME, sem seus dois pilares de sustentação, caducaria até o final de 2014, mantendo seu objetivo de estímulo ao setor privado pela via da política fiscal, que, amplamente sobrecarregada, contribuiria para o quadro de deterioração fiscal que se configurou diante do fracasso em expandir o PIB $^{6}$ (CARVALHO, 2018).

No segundo mandato de Dilma, a guinada à direita da política econômica, comandada pela equipe neoliberal de Joaquim Levy, levaria ao abandono de boa parte do instrumental social ou novo-desenvolvimentista que, em alguma medida, havia estado presente nos governos petistas até então. Em meio a essa miscelânea, a tipologia de políticas elaborada por Prates, Fritz e Paula (2019) é instrutiva para retratar a conjugação de políticas ortodoxas e desenvolvimentistas implementadas ao longo de mais de uma década. Como se pode observar, diante do uso variado e inconsistente de políticas de orientações ideológicas diversas, torna-se praticamente inócuo buscar caracterizar qualquer um dos governos petistas como novo ou social desenvolvimentista, sobretudo diante da constante presença de políticas ortodoxas ao longo dessas gestões.

\footnotetext{
${ }^{6}$ Conforme Carvalho (2018), a configuração desse quadro se deveu em grande medida à política de desonerações levada a cabo pelo governo no âmbito da NME, que se expandiu sem critério aparente a vastos setores da economia.
} 
Quadro 2 - Tipologia de políticas segunda Prates, Fritz e Paula (2019)

\begin{tabular}{|c|c|c|c|c|}
\hline $\begin{array}{c}\text { Políticas } \\
\text { macroeconômicas/ } \\
\text { Governos }\end{array}$ & $\begin{array}{c}\text { Governo Lula até a } \\
\text { crise financeira } \\
\text { global }\end{array}$ & $\begin{array}{c}\text { Governo Lula a } \\
\text { partir da crise global }\end{array}$ & $\begin{array}{c}\text { Primeiro mandato } \\
\text { de Dilma }\end{array}$ & $\begin{array}{c}\text { Segundo mandato } \\
\text { de Dilma }\end{array}$ \\
\hline Política monetária & ORT & ORT; ND; ORT & ND; ORT & ORT \\
\hline Política cambial & ORT & ORT; ND & ND; ORT & ORT \\
\hline Política fiscal & ORT & SD; ORT & ORT; (SD) & ORT \\
\hline Política social & SD & SD & SD & ORT \\
\hline Investimento Público & SD & SD & ORT \\
\hline Política financeira & SD & SD & SD & ORT \\
\hline Política industrial & ND & SD & SD & ORT \\
\hline
\end{tabular}

Fonte: Adaptado de Prates, Fritz e Paula (2019)

Notas: Estratégia entre parênteses indica a influência de certa estratégia de desenvolvimento. Legenda: ORT (políticas ortodoxas); SD (políticas social-desenvolvimentistas); ND (políticas novo-desenvolvimentistas). Separação por ";" indica sequência temporal de estratégias dentro de um período.

Em todo caso, o que se pode afirmar a partir da tipologia apresentada e das análises mencionadas é que o novo desenvolvimentismo esteve praticamente ausente do instrumental utilizado pelos governos de Lula e Dilma - à exceção de breves momentos em que se tentou reduzir a taxa Selic ou desvalorizar o câmbio. Já as políticas sociais e industriais, assim como os investimentos públicos levados a cabo durante o governo Lula, estiveram mais próximas ao social desenvolvimentismo, ainda que constantemente dentro de parâmetros macroeconômicos ortodoxos. Ao fim e ao cabo, conforme Paulani (2017):

Tomados em seu conjunto, os anos petistas revelam, portanto, um caráter errático e enorme oscilação: fidelidade integral, de início, aos cânones da prescrição ortodoxa (anos Palocci), inspiração Desenvolvimentista na sequência (anos PAC), reação embaralhada de ortodoxia com heterodoxia, mas certamente menos Desenvolvimentista que a etapa anterior, no primeiro período de Dilma, e novamente um retorno forte à ortodoxia nos últimos 16 meses de governo petista (com Joaquim Levy assumindo o Ministério da Fazenda). Ora, esse vaivém, esse bate-cabeça é a prova maior de que não se pode rotular de Desenvolvimentistas os anos petistas, porque é a prova maior de que faltava aí um projeto nacional de preferência nacional, popular e democrático, que tivesse permitido, desde seu início, o planejamento da intervenção econômica.

Em todo caso, se não se pode categorizar como desenvolvimentistas os governos em questão, torna-se inegável que elementos que desvirtuaram da ortodoxia econômica estiveram presentes no período. A relação destes com as agências de rating será objeto da próxima seção.

\section{As agências frente ao mix desenvolvimentista das gestões petistas}

Ao longo da década de 1990, a liberalização financeira da economia brasileira e o consequente ingresso do país no mercado de débito soberano, como emissor de títulos de dívida pública, trouxe como resultado a demanda pelos serviços das agências de rating, de modo que o país passou a ter sua credibilidade periodicamente avaliada por S\&P, Moody’s e Fitch. No século XXI, sobretudo a partir da quitação da dívida externa com o FMI (DE CONTI, 2015), essas empresas ganhariam cada vez maior proeminência como porta-vozes do mundo financeiro na esfera política e econômica nacionais. Nesse contexto, conforme a literatura apresentada na segunda seção deste artigo, as agências de rating, ideologicamente alinhadas à ortodoxia neoliberal, tendem a punir países que desvirtuam dos preceitos do Consenso de Washington - o que ocorre tanto mediante a atribuição de piores ratings quanto de críticas públicas à gestão da política econômica nos relatórios que divulgam e nas declarações de seus executivos à imprensa (SINCLAIR, 2005; YWATA, 2012). 
Ao longo dos governos do PT, no entanto, mesmo com a demonstrada combinação de variadas políticas de viés desenvolvimentista, o Brasil alcançou as melhores avaliações de sua história - cujo ápice se deu entre 2012 e 2014. Entre 2008 e 2009, em plena crise financeira global, o país obteve o grau de investimento atribuído pelas três agências. Com uma trajetória ascendente que começa em 2003 e só cessaria em 2014, o comportamento do rating brasileiro pode ser, assim, considerado um elemento de contradição das agências em relação ao substrato ideológico que as orienta. Os gráficos a seguir retratam o desempenho da classificação de risco do país, segundo S\&P, Moody's e Fitch, entre 2003 e 2016.

Gráfico 1 - Classificação de risco do Brasil segundo a $S \& P$ (2003-2016).

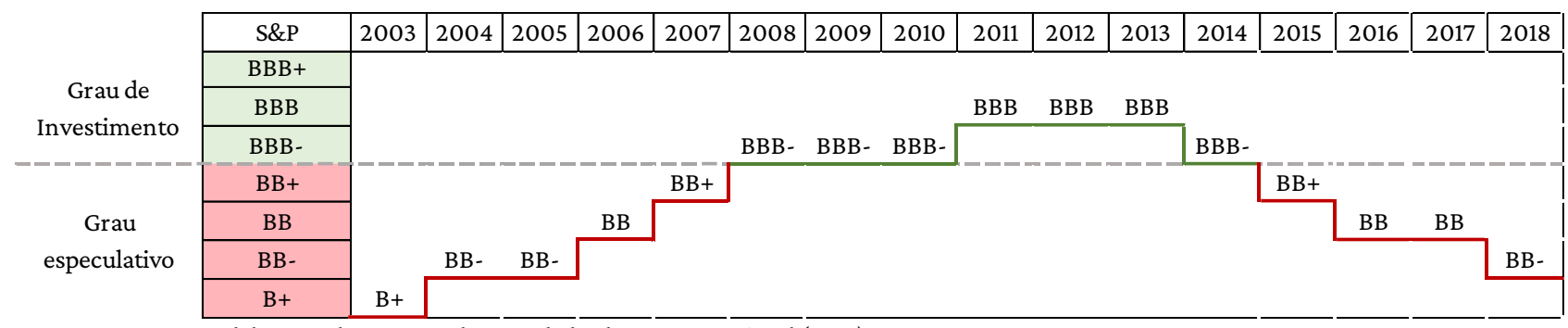

Fonte: Elaboração do autor com base em dados do Tesouro Nacional (2019).

Gráfico 2 - Classificação de risco do Brasil segundo a Moody's (2003-2016).

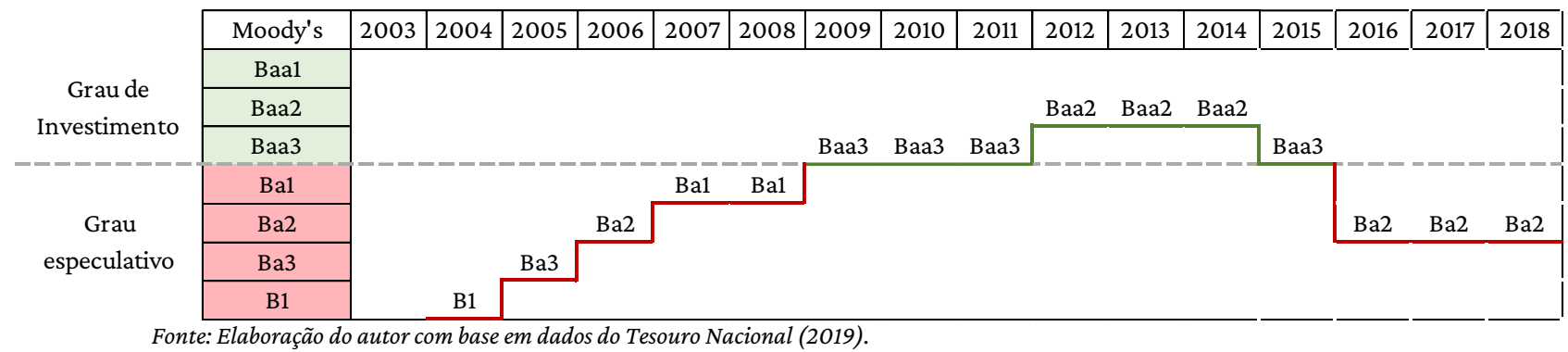

Gráfico 3 - Classificação de risco do Brasil segundo a Fitch (2003-2016).

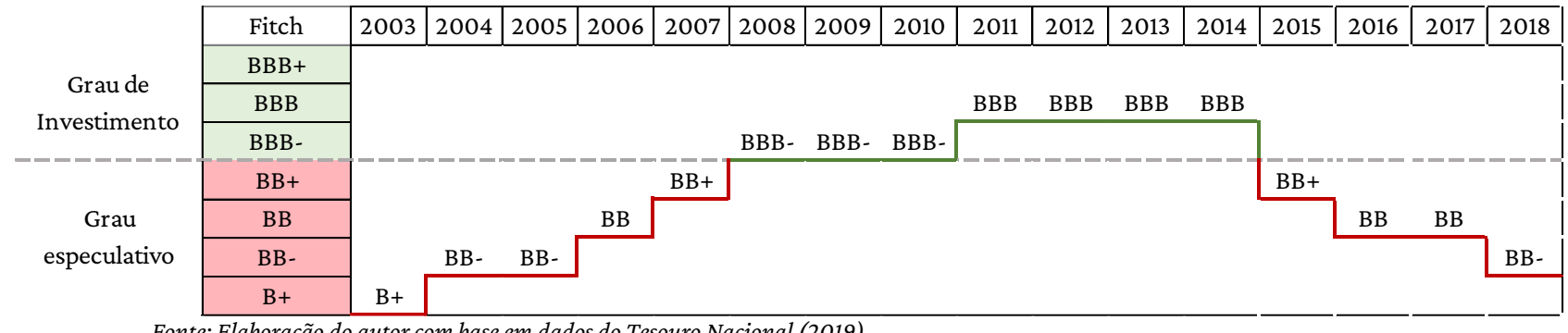

Fonte: Elaboração do autor com base em dados do Tesouro Nacional (2019).

Pode-se presumir que a explicação para a trajetória do rating brasileiro reside no real fortalecimento do perfil de crédito do país pari passu o crescimento econômico que logrou obter - cabe ressaltar, dentro dos parâmetros do tripé macroeconômico $^{7}$ - e, sobretudo, devido à resiliência demonstrada pela economia nacional no cenário da crise desencadeada em 2008. Nesse sentido, não seria razoável que as agências piorassem a nota de risco brasileira, a despeito de tal realidade, somente por conta de questões ideológicas em torno da gestão da política econômica nacional. Em outras palavras, é plausível considerar que o caráter pró-cíclico de sua atuação fez com que tenham atribuído ao país boas avaliações, independentemente das políticas econômicas adotadas - o que, ao fim e ao cabo, tornou inevitável a contradição na dimensão ideológica.

\footnotetext{
${ }^{7}$ Instituído em 1999 pelo governo de Fernando Henrique Cardoso (PSDB), o tripé macroeconômico é constituído por metas de inflação, câmbio flutuante e metas de superávit primário.
} 
Entretanto, chama a atenção que tal aspecto não tenha se restringido apenas aos ratings emitidos. Ao longo do período, os relatórios divulgados pelas empresas, em que justificavam as movimentações da nota brasileira, sugeriram tolerância ou até mesmo aprovação às políticas de caráter desenvolvimentista praticadas. Em relatório publicado em 11 de outubro de 2011, por exemplo, a Fitch destacava a força do país em lidar com choques externos a partir do uso de políticas contracíclicas e do manejo de controle de capitais na esteira da crise econômica global (FITCH, 2011).

Antes disso, em janeiro de 2009, a mesma Fitch Ratings apostava que a força do consumo doméstico teria papel determinante em fazer da economia brasileira mais robusta e estável. Diante do bom desempenho do país em meio ao caos global, a empresa aprovava as ações do governo no âmbito do Programa de Aceleração do Crescimento (PAC), assim como as políticas voltadas ao fortalecimento do mercado doméstico (FITCH, 2009a):

Esperamos que a dinâmica socioeconômica brasileira atraia investimento externo direto no longo prazo. Isto estimularia que projetos de desenvolvimento de infraestrutura cheguem também a áreas mais remotas, de modo a promover o crescimento econômico regional. De fato, o ambicioso PAC, que tem recebido ímpeto político adicional frente à desaceleração econômica, pode pavimentar o caminho para a elaboração de projetos que melhorem a infraestrutura física do Brasil. Além disso, a redução da pobreza e o aumento do poder de compra ajudarão a impulsionar a demanda do consumidor para além de 2013.

Em 20 de junho de 2012, foi a vez de a Moody's se manifestar avalizando as políticas social-desenvolvimentistas de dinamização do mercado interno implementadas durante o governo Lula, mediante a associação das boas avaliações do país e sua força econômica às políticas de distribuição de renda - em especial ao aumento do salário mínimo e ao acesso ao crédito: "A emergência do que vem sendo chamado de 'a nova classe média do Brasil' é um fator que deve fortalecer as perspectivas para a economia do país no médio prazo, uma vez que o mercado doméstico deve desempenhar um papel importante no futuro.". Com relação à política de aumento do salário mínimo, a empresa lembrou que esta constituía parte integral da estratégia de distribuição de renda do governo. Daí que o estabelecimento da regra que a atrelava à inflação e à média de crescimento do PIB dos dois anos anteriores foi elogiado, uma vez que acabava por lhe conferir uma maior transparência e previsibilidade: "A regra é inequivocamente positiva do ponto de vista do crédito soberano, ainda que, de tempos em tempos, possa resultar em aumentos substanciais do salário mínimo - como foi o caso neste ano - com seus correspondentes impactos nos gastos do governo" (MOODY’S, 2012a)

No mesmo ano, a analista chefe da S\&P, Lisa Schineller, assinava um artigo em que analisava o sucesso da economia brasileira, que não poderia ser atribuído, segundo a autora, apenas aos preços das commodities exportadas. Assim como a Moody's, Schineller (2012) observava a força do mercado doméstico do país, fortalecido pelas políticas socialdesenvolvimentistas levadas a cabo até então:

\begin{abstract}
Essas políticas engendraram um fundamento mais sólido no crescimento promovido por uma demanda doméstica de base ampla. Quase 40 milhões de brasileiros se deslocaram para a classe média. A diminuição da pobreza e da desigualdade, que se encontram nos níveis mais baixos em 50 anos, ampliou a base de consumo do país para além da classe média-alta. O Bolsa Família, ainda que atinja 50 milhões de brasileiros, corresponde a apenas $0,4 \%$ do PIB e não pode levar o crédito por essa reviravolta nos indicadores sociais. $\mathrm{O}$ aumento sólido do salário mínimo - e às vezes excessivo - e a baixa inflação têm sido cruciais. [...] Ao mesmo tempo, melhores condições macroeconômicas facilitam o crescimento do crédito, particularmente aos novos empregados formais e às empresas. A oferta de crédito duplicou para cerca de 50\% do PIB, contribuindo para uma demanda doméstica mais firme no país.
\end{abstract}

Paralelamente, a analista da S\&P criticava as taxas de juros no Brasil, que figuravam entre as mais altas do planeta e que refletiam distorções no mercado de crédito. Outro alvo de críticas foi a sobrevalorização do real, que decorreria dos altos preços das commodities exportadas pelo país. Em relatório do dia 21 de novembro de 2012, a Moody's também apoiava explicitamente a redução da taxa Selic que já vinha sendo posta em prática pelo governo, lembrando que a ação "poderia ter implicações favoráveis ao rating soberano do Brasil" (MOODY’s, 2012b). Cabe lembrar que se tratam dos dois pilares da NME - redução dos juros e desvalorização cambial - que estava sendo implementada pelo governo Dilma no período, o 
que pode ser interpretado como um aval das empresas à política econômica do governo. Como visto na seção anterior, tratam-se de diagnósticos que vão ao encontro de postulados novo-desenvolvimentistas.

Ademais, as medidas voltadas ao estímulo de investimentos no setor privado, em especial a política de desonerações levada a cabo, foram, inicialmente, elogiadas nos relatórios das agências - até que, com o passar do tempo, resultassem no quadro de deterioração fiscal que marcaria o governo já em 2014. Sobre este tema, a avaliação inicial da Moody's (2012b) era positiva:

A decisão do governo de reduzir os impostos representa um afastamento das práticas anteriores. Caso sejam mantidas, as reduções poderiam impactar significativamente o desempenho econômico visto que a elevada carga de impostos do Brasil tem sido considerada um impedimento para o crescimento e para investimentos.

A política de acúmulo de reservas internacionais foi outro frequente tema de destaque na análise das agências acerca do bom desempenho da economia brasileira na esteira da crise econômica global. Em seu relatório de maio de 2009, a Fitch destacava o efeito de amortecimento conferido pelas reservas do país diante de possíveis movimentos de saída de capitais (FITCH, 2009b). Também a Moody's, nos dois relatórios mencionados, observou os benefícios do acúmulo de reservas, que deu ao governo margem de manobra para agir contraciclicamente no contexto adverso de crise. Com efeito, trata-se de um elemento que perpassa boa parte dos relatórios das três agências de rating ao longo dos governos petistas ao menos até meados do governo Dilma.

Cabe, neste ponto, destacar que a política de acúmulo de reservas resultou do ingresso de divisas decorrente dos altos preços das commodities exportadas pelo país e de condições favoráveis de liquidez internacional. Como teorizado por Campello (2015), tais teriam sido os fatores que conferiram ao governo a margem de manobra necessária à implementação das políticas de viés desenvolvimentista até aqui mencionadas e que tornaram investidores mais tolerantes ao risco de incluir, em seus portfólios, títulos de economias emergentes, como a brasileira. Diante deste cenário externo favorável, em meio ao qual a economia crescia por vezes desvirtuando da ortodoxia econômica, as agências de rating, como demonstrado, não apenas atuaram pró-ciclicamente na classificação de risco do país, mas também adaptaram seus discursos em prol das estratégias levadas a cabo pelo governo.

Este comportamento cessaria, no entanto, a partir da reversão da conjuntura internacional favorável, com a gradativa deterioração dos termos de troca das exportações do país e da contração da liquidez internacional, decorrente do anúncio do desmonte da política de expansão monetária dos Estados Unidos. Diante disso, a partir de meados de 2013, o já observável fracasso da NME em promover o crescimento da economia passaria a pautar os relatórios das agências. De fato, o quadro de deterioração fiscal que se estabeleceria e que, a partir de então, apenas se acentuaria, fez das ações desenvolvimentistas constantes alvos de críticas, sobretudo dado o grau de intervencionismo estatal que requeriam na esfera econômica - e que, portanto, conflitavam diretamente com o receituário do Consenso de Washington. Em outras palavras, o espaço aberto ao desenvolvimentismo pela pró-ciclicidade do comportamento das agências, fruto de circunstâncias específicas da conjuntura internacional, fechava-se. Tal realidade se refletiu no posicionamento da S\&P (2014) no contexto das eleições presidenciais de 2014:

Acreditamos que o perfil das politicas de um segundo mandato de Dilma seria similar ao seu atual governo, no qual a Presidente continuaria supervisionando intensamente as decisões políticas. Embora esperemos certas mudanças na equipe e nas políticas econômicas, em geral estimamos "mais do mesmo" em termos de política desigual. Acreditamos que um governo de Aécio ou Campos poderia buscar uma política econômica mais consistente e orientada ao mercado, com um maior direcionamento inicial para a confiança do investidor doméstico e internacional.

Por outro lado, a guinada à direita na condução da política econômica que marcaria o breve segundo mandato de Dilma renderia elogios das agências, conforme nova manifestação da S\&P em 23 de março de 2015 (S\&P, 2015): 


\begin{abstract}
A sinalização da política econômica mudou significativamente, o que não fazia parte de nossas expectativas de caso base. Uma ampla correção na política vem ocorrendo para fortalecer o compromisso fiscal, tanto dentro quanto fora do orçamento, e eliminar várias distorções econômicas, que inclui os preços administrados artificialmente omitidos. Para conter a inflação e as expectativas de inflação, o Banco Central embarcou em outro ciclo de aperto. Este também vem moderando sua intervenção do mercado cambial (mediante a redução da oferta de dólares dos Estados Unidos por meio de programas de Swap cambial), facilitando a desvalorização cambial.
\end{abstract}

Mais do que isso, a manutenção de Joaquim Levy, prócer da ortodoxia neoliberal, à frente do Ministério da Fazenda, chegou a ser sugerida, em outubro de 2015, como condição para a manutenção da classificação de risco do país, como declarou Shelly Shetty, analista da Fitch, ao Valor Econômico (2015): "se Levy sair ou a sua equipe, vamos ter que analisar o novo ambiente e a orientação que a nova equipe terá". Este tipo de preocupação decorria do fracasso da estratégia de contração fiscal expansionista posta em prática pela equipe do ministro em recuperar a economia. Embora não se tenha a pretensão de atribuir o caos econômico do segundo governo Dilma apenas à referida estratégia neoliberal levada a cabo, sobretudo diante do cenário de crise política e de governabilidade que marcou o contexto (SINGER, 2018), é notório que a mesma contribuiu decisivamente nesse sentido (CARVALHO, 2018; MELLO; ROSSI, 2017).

Reativamente, as agências voltariam suas críticas às políticas heterodoxas implementadas ao longo do primeiro mandato da presidente, isentando a gestão Levy de qualquer culpa, à medida em que rebaixava o rating brasileiro, conforme o caráter pró-cíclico de seu comportamento (MACHADO, 2018). Com efeito, já em julho de 2014, a S\&P justificava o primeiro rebaixamento da nota de risco brasileira em mais de uma década colocando em xeque a credibilidade do governo, podendo-se também depreender de sua manifestação uma implícita avaliação negativa dos resultados da política de desonerações fiscais então implementada - e que fora outrora elogiada pela Moody’s. Nas palavras da S\&P (2014):

A deterioração fiscal do Brasil nos últimos anos inclui, de certa forma, déficits mais altos - como resultado de um superávit fiscal primário menor (ou sem levar em conta os juros) - e as atividades extraorçamentárias recorrentes. A credibilidade do governo com relação à condução da política fiscal foi sistematicamente enfraquecida, pois o governo isentou vários itens de receita e gasto de sua meta fiscal, além de ter reduzido a própria meta ao longo do tempo. O uso persistente de bancos estatais, financiado por recursos "abaixo da linha" do Tesouro Nacional, também prejudicou a credibilidade e a transparência das políticas.

No mesmo sentido, no dia 17 de fevereiro de 2016, a S\&P atribuía mais uma baixa do rating brasileiro ao "legado de decisões políticas anteriores, durante a primeira administração de Rousseff" (S\&P, 2016). Nesse contexto, à altura do impeachment de Dilma, a classificação de risco do Brasil já afundara novamente no grau especulativo de onde saíra durante os próprios governos petistas, como retratam os gráficos 1, 2 e 3.

Em suma, o que se pode depreender da atuação das agências de rating ao longo do período de maior ativismo desenvolvimentista nos governos petistas é que estas empresas, a despeito de seu alinhamento ideológico, foram lenientes com tais políticas enquanto a economia apresentava bons resultados e desfrutava da menor aversão ao risco por parte do mercado financeiro. Nesse contexto, não apenas a nota de risco atribuída ao país refletiu aprovação ao mix ideológico de políticas econômicas então implementado, mas também os relatórios e declarações de seus representantes demonstravam tolerância e estímulo ao instrumental desenvolvimentista utilizado.

Uma vez revertido o sucesso econômico e as circunstâncias internacionais que contribuíram para o mesmo, contudo, as agências não tardariam a atribuir a estagnação econômica e deterioração fiscal às políticas de viés desenvolvimentista que vinham sendo implementadas. Em outras palavras, torna-se perceptível que o caráter pró-cíclico de seu comportamento abriu espaço para que o mix de políticas desenvolvimentistas fosse visto de forma positiva quando a economia ia bem, ainda que, revertido o panorama favorável, a ortodoxia neoliberal tenha voltado a orientar seu comportamento e avaliações. 


\section{Conclusão}

$O$ artigo refletiu acerca do comportamento das agências de rating frente à adoção de políticas desenvolvimentistas pelos governos do PT - o que ocorreu, como apresentado, mediante uma constante conjugação com políticas ortodoxas. À luz desta experiência, a hipótese de que o caráter pró-cíclico da atuação dessas empresas abre espaço para eventuais desvirtuamentos da ortodoxia econômica, ainda que possivelmente condicionados pela conjuntura externa, ganha sustentação. Nesse sentido, segundo a perspectiva da ação das agências de rating, sugere-se a viabilidade da adoção de políticas desenvolvimentistas no contexto de globalização financeira - que se configura, como discutido na segunda seção do trabalho, de forma hostil a práticas desviantes da ortodoxia econômica, sobretudo em se tratando de economias emergentes.

Deve-se ressaltar que conclusões mais robustas nesse sentido demandariam a ampliação da quantidade de casos levados em conta, assim como a contemplação dos mesmos em um espaço temporal mais extenso, no qual se possa observar alterações no comportamento das agências segundo seu viés pró-cíclico. Em todo caso, não se pode descartar aspectos generalizáveis do caso estudado. Em se tratando de atores que operam em escala global, é de se esperar que as lições extraídas da experiência brasileira - ainda que curta - sejam também aplicáveis às de demais países.

Destas constatações, ademais, emergem novas possibilidades de pesquisa. Além da referida ampliação de casos, uma diversificação de métodos poderia lançar luz às perspectivas de policy space que se apresenta a economias periféricas - a partir, por exemplo, da realização de entrevistas com atores provenientes tanto das agências quanto de governos dos países em questão. Além disso, pesquisas que considerem a postura de outras agências de rating - como a Dagong, de origem chinesa - frente a políticas desenvolvimentistas poderiam esclarecer eventuais motivações geopolíticas por detrás das agências norte-americanas consideradas neste trabalho. Em todo caso, espera-se, enfim, ter-se contribuído para um melhor entendimento acerca desses atores ainda pouco explorados pela literatura, assim como das perspectivas que se abrem, no contexto de globalização financeira, à implementação de políticas de viés desenvolvimentista.

\section{Referências}

BARTA, Zsófia; JOHNSTON, Alison. Rating politics? Partisan discrimination in credit ratings in developed economies. Comparative Political Studies, pp. 1-34, 2017

BASTOS, Pedro P. Z. A economia política do novo-desenvolvimentismo e do social-desenvolvimentismo. Economia e Sociedade, Campinas, v. 21, Número Especial, p. 779-810, 2012.

BINICI, Mahir; HUTCHISON, Michael; MIAO, Evan W. Are credit ratings agencies discredited? Measuring market price effects from agencies sovereign debt announcements. BIS Working Paper 704, 2018.

BLYTH, Mark. Austeridade: a história de uma ideia perigosa. Autonomia Literária, 2017.

BRESSER-PEREIRA, Luiz C. From old to new developmentalism in Latin America. In Ocampo, J. A. e Ros, J. (org.). Handbook of Latin America Economics, Oxford: Oxford University Press, 2009.

BRESSER-PEREIRA, Luiz C. O governo Dilma frente ao tripé macroeconômico e à direita liberal e dependente. Novos Estudos, 95, pp. 5-14, 2013.

BRESSER-PEREIRA, Luiz C.; GALA, Paulo. Macroeconomia estruturalista do desenvolvimento. Revista de Economia Política, v. 30 , n. 4, pp. 663-686, 2010 .

CAMPELLO, Daniela. The politics of market discipline in Latin America: globalization and democracy. Cambridge University Press, 2015.

CARNEIRO, Ricardo. Velhos e novos desenvolvimentismos. Economia e Sociedade, n. 21, pp. 749-778, 2012.

CARVALHO, Fernando C. de. Mudanças no papel e nas estratégias do FMI e perspectivas para países emergentes. In: FERRARI FILHO, Fernando; DE PAULA, Luiz F. (orgs.). Globalização financeira: ensaios de macroeconomia aberta. Editora Vozes, 2004.

CARVALHO, Laura. Valsa brasileira: do boom ao caos econômico. Editora Todavia, 2018. 
DE CONTI, Bruno. A disciplina imposta à periferia: do FMI às agências de rating. In: BELLUZZO, Luiz G.; BASTOS, Pedro P. Z. (orgs.). Austeridade para quem? Balanço e perspectivas do governo Dilma Rousseff. São Paulo: Carta Maior, 2015.

EICHENGREEN, Barry; HAUSMANN, Ricardo; PANIZZA, Ugo. Currency Mismatches, Debt Intolerance, and Original Sin: Why They Are Not the Same and Why It Matters. In: EDWARDS, Sebastian (ed.). Capital Controls and Capital Flows in Emerging Economies: Policies, Practices and Consequences. The University of Chicago Press, 2007.

FERRI, G.; LIU, G.; STIGLITZ, J. E. The procyclical role of rating agencies: evidence from the east asian crisis. Economic Notes, v. 28 , n. 3., pp. 335-355, 1999 .

FITCH. 10 Years Forecast - The Brazilian Economy to 2018. FitchSolutions, 2009a.

FITCH. Fitch Ratings affirms Brazil at ‘BBB-’; Outlook Stable. FitchSolutions, 2009b.

FITCH. Latin America Sovereign Ratings in a Weakening Global Economy. FitchRatings, 2011.

FITCH. Rating Definitions. FitchRatings, 2020. Disponível em $<$ https://www.fitchratings.com/products/rating-definitions $>$. Acesso em: 20 jan. 2020.

FONSECA, Pedro D. Desenvolvimento: a construção do conceito. In Calixtre, B.B. et al (org.). Presente e Futuro do Desenvolvimento Brasileiro. Brasília: IPEA, 2014.

FRIEDMAN, Thomas L. Foreign affairs; Don't Mess with Moody's. The New York Times, 1995. Disponível em <https://www.nytimes.com/1995/02/22/opinion/foreign-affairs-don-t-mess-with-moody-s.html>. Acesso: 17 nov. 2018.

FRITZ, Barbara; PAULA, Luiz F. de; PRATES, Daniela M. Developmentalism at the Periphery Can Productive Change and Income Redistribution be Compatible with Global Financial Asymmetries? Desigualdades.net, Working Paper n. 101, 2017.

KRUCK, Andreas. Resilient blunderers: credit rating fiascos and rating agencies' institutionalized status as private authorities, Journal of European Public Policy, 2016. Disponível em <http://dx.doi.org/10.1080/13501763.2015.1127274 >. Acesso em: 23 fev. 2019.

MACHADO, Pedro L. N. A política da classificação de risco: uma análise da atuação das agências de rating ao longo dos governos de Dilma Rousseff (2011-2016). Dissertação de Mestrado em Relações Internacionais, Universidade Federal de Santa Catarina, 2018.

MELLO, Guilherme; ROSSI, Pedro. Do industrialismo à austeridade: a política macro do governo Dilma. Texto para discussão do IE da Unicamp, n. 309, 2017.

MOODY'S. Credit analysis: Brazil. Moody's Investor Service, 2012a.

MOODY'S. Moody's afirma rating Baa2 do Brasil e mantém uma perspectiva positiva. Moody's Investor Service, 2012b. Disponível em $<$ https://www.moodys.com/research/Moodys-afirma-rating-Baa2-do-Brasil-e-mantm-uma-perspectiva--PR_260540>. Acesso em: 25 mai. 2019.

MOODY'S. Rating Scale and Definitions. Moody's Investor Service, 2020. Disponível em:

<https://www.moodys.com/sites/products/productattachments/ap075378_1_1408_ki.pdf>. Acesso em: 18 jan. 2020.

MOSLEY, Layna. Global capital and national governments. Cambridge University Press, 2003.

OCAMPO, Jose A. Balance of payments dominance: its implications for macroeconomic policy. 2011. Disponível em: $<$ https://bibliotecadigital.fgv.br/dspace/handle/10438/16268>. Acesso em: 14 mar. 2020.

PAUDYN, Bartholomew. Credit ratings and sovereign debt: the political economy of creditworthiness through risk and uncertainty. Palgrave Macmillan, 2014.

PAULA, Luiz F. de; FRITZ, Barbara; PRATES, Daniela M. Center and Periphery in International Monetary Relations: Implications for Macroeconomic Policies in Emerging Economies. Desigualdades.net, Working Paper n. 80, 2015.

PAULA, Luiz F.; SANTOS, Fabiano; MOURA, Rafael. The Developmentalist Project of the PT Governments: An Economic and Political Assessment. Latin American Perspectives, v. 47, n. 2, 2020.

PAULANI, Leda M. A experiência brasileira entre 2003 e 2014: neodesenvolvimentismo? Cadernos do Desenvolvimento, v. 12, n. 20, pp. 135-155, 2017.

PRATES, Daniela M.; FRITZ, Barbara; PAULA, Luiz F. de. O desenvolvimentismo pode ser culpado pela crise? Uma classificação das políticas econômica e social dos governos do PT ao governo Temer. 2019. Disponível em:

$<$ http://www.luizfernandodepaula.com.br/ups/prates-et-al-2019-td-ie-ufrj-o-desenvolvimentismo-pode-ser-culpado-pelacrise.pdf >. Acesso em: 15 jul. 2019.

RODRIK, Dani. The globalization paradox: why global markets, states and democracy can't coexist. Oxford University Press, 2012.

S\&P. Análise complementar: República Federativa do Brasil. Standard \& Poor's Ratings Services, 2014 
S\&P. Ratings de longo prazo do Brasil reafirmados; perspectiva permanece estável. S\&P Global Ratings, 2015. Disponível em: <https://www.standardandpoors.com/pt_LA/web/guest/article/-/view/type/HTML/sourceAssetId/1245383488002>. Acesso em: 23 mai. 2019.

S\&P. Ratings de longo prazo do Brasil rebaixados para 'BB', dados os significativos desafios políticos e econômicos; perspectiva negativa. S\&P Global Ratings, 2016.

S\&P. S\&P Global Ratings Definitions. S\&P Global Ratings, 2020. Disponível em:

<https://www.standardandpoors.com/en_US/web/guest/article/-/view/sourceId/504352>. Acesso em: 20 jan. 2020.

SCHINELLER, Lisa. Brazil's economic success is based on more than the demand for natural resources. Americans Quarterly. 2012. Disponível em: <https://www.americasquarterly.org/node/3811>. Acesso em: 16 jun. 2019.

SINCLAIR, Timothy J. The new masters of capital: american bond rating agencies and the politics of creditworthiness. Cornell University Press, 2005.

SINGER, André. O lulismo em crise: um quebra-cabeça do período Dilma (2011-2016). São Paulo: Companhia das Letras, 2018.

STREECK, Wolfgang. Tempo comprado: a crise adiada do capitalismo democrático. Editora Boitempo, 2018.

TESOURO NACIONAL. Classificação de risco da República Soberana do Brasil. 2019. Disponível em: <http://www.tesouro.gov.br/en/classificacao-de-risco>. Acesso em: 14 jun. 2019.

VAALER, Paul. M.; SCHRAGE, Burkhard; N., \& BLOCK, Steven A. Elections, opportunism, partisanship and sovereign ratings in developing countries, Review of Development Economics, v. 10, p. 154-170, 2006.

VALOR ECONÔMICO. Fitch diz que, sem Levy, teria que analisar o novo ambiente. 2015. Disponível em: <https://www.valor.com.br/financas/4273094/fitch-diz-que-sem- levy-teria-que-analisar-o-novo-ambiente>. Acesso em: 18 abr 2018.

WILLIAMSON, John. Democracy and the Washington Consensus. World Development, 1993, v. 21, no 8, pp. 1329-1336.

YWATA, Ricardo K. Ordem Mundial e Agências de Rating: o Brasil e as agências na era global (1996-2010). São Paulo: Editora Senac, 2012.

Funções de colaboração exercidas 